\title{
CORRIGENDUM
}

\section{Active Avoidance Learning and Activity Level ${ }^{1}$}

\section{Craig Jensen ${ }^{2}$}

An abstract of the above paper appeared in the section Behavior Genetics Association Abstracts. On line 14 of the abstract, read $r=0.80$ instead of $r=0.08$. Also, on lines 6 and 9 of the abstract, read $\omega^{2}$ instead of $\omega_{2}$.

\footnotetext{
${ }^{1}$ An abstract of this paper appeared in Behavior Genetics 5(1):98 (1975).

${ }^{2}$ Pace University/Westchester, Pleasantville, New York.
} this publication may be reproduced, stored in a retrieval system, or transmitted, in any form or by any means, electronic, mechanical, photocopying, microfilming, recording, of otherwise, without written permission of the publisher. 